Research Article

\title{
Evaluation of the anti-inflammatory activity of dipyridamole in acute and chronic experimental models in albino rats
}

\author{
Vishwaprakash M. K.*, Laveesh M. R., Somashekara S. C.
}

\begin{abstract}
Department of Pharmacology, Malabar Medical College and Research Institute, Modakkallur673315, Kozhikode, Kerala, India

Received: 28 July 2016 Accepted: 02 August 2016

\section{*Correspondence to: Dr. Vishwaprakash M.K., Email: vishwapujar79@ gmail.com}

Copyright: (C) the author(s), publisher and licensee Medip Academy. This is an openaccess article distributed under the terms of the Creative Commons Attribution NonCommercial License, which permits unrestricted noncommercial use, distribution, and reproduction in any medium, provided the original work is properly cited.

\begin{abstract}
Background: Cyclic nucleotides, particularly cyclic AMP, have an important regulatory role in a variety of inflammatory processes. The concentration of cAMP can be influenced by either inhibition of phosphodiesterase enzyme or by activating adenylate cyclase enzyme. The present study was undertaken to evaluate the anti-inflammatory activity of dipyridamole a selective (PDE6) phosphodiesterase inhibitor; on acute and chronic experimental models in albino rats.

Methods: Anti-inflammatory activity was evaluated by using carrageenaninduced rat hind paw oedema model for assessing acute anti-inflammatory activity. The normal paw volume ( 0 hour) and the volume of injected paw (3 hour) were measured by using plethysmometer. Assessment of chronic antiinflammatory activity was carried out using formalin-induced rat paw edema model. The paw volume was measured at 0 hour and on $7^{\text {th }}$ day after injection of formalin by using plethysmometer. The results obtained were compared with the control and the standard anti-inflammatory drug, indomethacin.

Results: The results indicated that dipyridamole has anti-inflammatory action in both acute and chronic inflammatory models. But statistically significant anti-inflammatory action was seen only with the chronic inflammatory model $(0.11 \pm 0.05$ units, $\mathrm{p}=0.02)$. Anti-inflammatory activity could be due to inhibition of inflammatory cells and mediators especially histamine, leukotrienes and eicosanoids.

Conclusions: Selective phosphodiesterase inhibitors could be a source of valuable anti-inflammatory drugs, in addition to currently available steroidal and non-steroidal anti-inflammatory agents.
\end{abstract}

Keywords: Cyclic nucleotides, Phosphodiesterase, Dipyridamole, Indomethacin, Carrageenan, Formalin, Plethysmometer

\section{INTRODUCTION}

Cyclic nucleotide phosphodiesterase has fuelled a lot of interest and opportunity since Sutherland et al reported the presence of cyclic adenosine monophosphate (cAMP) in liver extracts as a second messenger, later Sutherland identified cyclic nucleotide hydrolysing activity by phosphodiesterase enzyme (PDE). ${ }^{1}$ Cyclic nucleotides cAMP and cGMP, are second messengers which have diverse physiological role. Such diversity of functions depends on the type of $\mathrm{G}$ protein (Gs or $\mathrm{Gi}$ ) with which the receptor is coupled, the set of protein kinase A (PKA) target enzymes in the cells and confinement of the protein kinase to a specific region of the cell by scaffold proteins.
Thus cyclic nucleotides are responsible for various physiological functions occurring through hormones, neurotransmitters, autacoids and drugs. As cyclic nucleotides are inactivated by PDEs, there is a corresponding decrease in protein kinase activity resulting in altered function of cells.

Cyclic nucleotides, particularly cyclic AMP, have an important regulatory role in virtually all cell types involved in the pathophysiology of asthma, a chronic inflammation. $^{2}$ Recent studies have revealed that cyclic nucleotides, especially cyclic AMP act as a second messenger for a variety of inflammatory mediators and cytokines and have been shown to modulate models of 
immune and non-immune inflammation in vivo and a variety of cellular processes in vitro, however little evidence is there in support of cyclic GMP. ${ }^{2,3}$ During inflammation, production of cyclic AMP in inflammatory cells is stimulated by histamine and $\mathrm{E}$ series prostaglandins. Rise in intracellular cAMP is usually transient because of the enzymatic activity of phosphodiesterase. So concentration of cAMP can be influenced by inhibition of phosphodiesterase and drugs activating adenylate cyclase, an enzyme required in conversion of adenosine triphosphate to cAMP. ${ }^{3}$ Until the discovery of 11 PDEs isoenzyme, with differing tissue distributions, phosphodiesterase inhibitors were less popular due to their non-specific inhibition of enzymes (e.g. theophylline), resulting in unwanted side effects. Recognition of the presence of a wide range of phosphodiesterase isoenzymes in different tissues and subcellular compartments has fuelled a lot of interest in PDEs as drug targets. Though there has been tremendous work going on with phosphodiesterase and its inhibitors, there are still many uncovered areas of therapeutic importance. With respect to inflammation, PDE4 and to a lesser extent PDE3 have a major role in metabolizing cAMP in all immune competent cells..$^{2-4}$ Dipyridamole, a PDE5 and PDE6 inhibitor, has also shown to inhibit lymphocyte recruitment, activation, and secretion of proinflammatory mediators.

Hence, the present study was undertaken to assess the anti-inflammatory effect of the phosphodiesterase inhibitors, dipyridamole (PDE5 and PDE6 enzyme inhibitor) on acute and chronic inflammation.

\section{METHODS}

\section{Animals}

Wistar albino rats of the either sex, weighing 100-200 gm, were used for the study. Albino rats were obtained from National Institute of Nutrition, Hyderabad and were maintained at central animal house of Malabar Medical College and research centre, Modakkallur, Kozhikode. The wistar albino rats were provided with standard laboratory chow and tap water ad libitum. Animals were maintained on a 12-hour light/dark cycle at optimum humidity and temperature levels. Protocols used in this study were approved by the appropriate ethical committees.

Anti-inflammatory activity was evaluated by using carrageenan/formalin induced rat hind paw oedema model for assessing acute and chronic anti-inflammatory activity respectively. Paw edema was measured by using a plethysmometer. Before the start of the procedure, a line was marked at the level of the right malleolus to facilitate the dipping of the foot up to the same mark every time. Wistar albino rats were fasted overnight and divided into four groups consisting of six animals each and treated as follows:
- $\quad$ First group served as control and received $4 \%$ gum acacia suspension by mouth.

- Second group received dipyridamole in a dose of $40 \mathrm{mg} / \mathrm{kg}$ body weight prepared as a suspension in $4 \%$ gum acacia.

- Third group received indomethacin $(10 \mathrm{mg} / \mathrm{kg}$ body weight), prepared as a suspension in $4 \%$ gum acacia.

- Fourth group received both dipyridamole $(40 \mathrm{mg} / \mathrm{kg}$ body weight) and indomethacin $(10 \mathrm{mg} / \mathrm{kg}$ body weight) prepared as a suspension in $4 \%$ gum acacia separately.

All the drugs were administered orally through a small soft rubber catheter, about an hour before the injection of carrageenan $(0.1 \mathrm{ml}$ of $1 \%)$ / formalin $(0.1 \mathrm{ml}$ of $2 \%)$. The volume of the suspension administered in control and other groups was kept constant. Animals with formalin induced rat paw edema, received drugs for 7 days.

\section{Carrageenan induced rat paw edema}

The right hind paw edema was produced by injecting $0.1 \mathrm{ml}$ of $1 \%$ of carrageenan subcutaneously into the plantar aspect of right hind paw. ${ }^{5}$ The hind paw volume obtained immediately after sub plantar injection of carrageenan was taken as reading at 0 hour for both control and the treated rats. The paw volume was measured at the end of 3 hours after the injection of the phlogistic agent both in control and test animals. The volume changes occurring at 0 hour and at the end of 3 hrs were compared and the increase in edema over the initial reading was recorded.

\section{Formalin induced rat paw edema}

Inflammation is produced by injecting a $0.1 \mathrm{ml}$ of $2 \%$ formalin, subcutaneously into the plantar aspect of right hind paw on day 1 and 3 of the procedure. The hind paw volume obtained immediately after sub plantar injection of formalin was taken as reading at 0 hour and was once again measured at $7^{\text {th }}$ day after the injection of the phlogistic agent. The volume changes occurring at 0 hour and at $7^{\text {th }}$ day were compared and the difference in edema over the initial reading was recorded.

\section{The reading was taken as follows}

Each time before dipping right hind paw, reading in plethysmometer was zeroed by pushing PROG button (short, quick push) followed by pushing CLEAR button. By comparing the edema produced in control and treated groups, percent inhibition of edema was calculated using following formula

$$
\text { Percent inhibition }=\frac{V c-V t}{V c} \times 100
$$

where, 
- $\quad \mathrm{Vc}=$ Volume of paw edema in control animals.

- $\mathrm{Vt}=$ Volume of paw edema in drug treated animals.

\section{Statistical analysis}

The results of anti-inflammatory activity was expressed as mean increase in paw volume \pm SEM. Analysis of variance (ANOVA) followed by post hoc Tukey's test was used for statistical evaluation. P-value less than 0.05 were considered as significant and P-value less than 0.01 was considered as highly significant.

\section{RESULTS}

\section{Carrageenan-induced paw edema in rats}

Compared to group 2, 3 and 4, there was a statistically significant increase in mean paw volume following the administration of only $4 \%$ gum acacia (control group) in acute inflammation models, from $1.22 \pm 0.05$ units to $1.42 \pm 0.04$ units $(\mathrm{p}=0.001)$; an increase of $0.20 \pm 0.07$ units.

Table 1: Mean pre and post paw volume in different groups of acute experimental models.

\begin{tabular}{|c|c|c|c|c|c|c|}
\hline \multirow{2}{*}{ Acute inflammation groups } & & \multirow{2}{*}{ Mean } & \multirow{2}{*}{ Std. deviation } & \multicolumn{2}{|c|}{ Paired differences } & \multirow{2}{*}{$\begin{array}{l}\text { Paired t test } \\
\text { p-value }\end{array}$} \\
\hline & & & & Mean & Std. deviation & \\
\hline \multirow{2}{*}{ Control (4\% gum acacia) } & Pre & 1.22 & 0.05 & \multirow{2}{*}{0.20} & \multirow{2}{*}{0.07} & \multirow{2}{*}{$\begin{array}{l}0.001 \\
\text { (Significant) }\end{array}$} \\
\hline & Post & 1.42 & 0.04 & & & \\
\hline \multirow{2}{*}{ Dipyridamole } & Pre & 1.16 & 0.07 & \multirow{2}{*}{0.09} & \multirow{2}{*}{0.12} & \multirow{2}{*}{0.14} \\
\hline & Post & 1.25 & 0.13 & & & \\
\hline \multirow{2}{*}{ Indomethacin } & Pre & 1.06 & 0.03 & \multirow{2}{*}{0.06} & \multirow{2}{*}{0.08} & \multirow{2}{*}{0.125} \\
\hline & Post & 1.12 & 0.06 & & & \\
\hline \multirow{2}{*}{ Dipyridamole and Indomethacin } & Pre & 1.05 & 0.03 & \multirow{2}{*}{0.05} & \multirow{2}{*}{0.11} & \multirow{2}{*}{0.357} \\
\hline & Post & 1.10 & 0.09 & & & \\
\hline
\end{tabular}

But there was no significant difference in paw volume before and after administration of dipyridamole $(1.16 \pm 0.07$ units vs $1.25 \pm 0.13$ units, $\mathrm{p}=0.14)$ indomethacin $(1.06 \pm 0.03$ units vs $1.125 \pm 0.06$ units, $\mathrm{p}=0.125)$ and combination of dipyridamole and indomethacin $(1.05 \pm 0.03$ units vs $1.10 \pm 0.09$ units, $\mathrm{p}=0.357$ ) in acute inflammation models. So results clearly indicates the antiinflammatory action of drugs used in group 2, 3 and 4 (Table 1).
Mean change in Paw volumes in control and test groups of acute inflammation model was analysed using one way ANOVA test with post hoc Tukey's test for pairwise comparison. Although, there was no statistically significant difference in mean change in paw volumes between the groups $(p=0.058)$, percentage of inhibition of edema was seen highest in combination of both dipyridamole and indomethacin (Table 2).

Table 2: Mean change in paw volumes in different groups of acute experimental models.

\begin{tabular}{|c|c|c|c|c|}
\hline Acute inflammation groups & Mean & Percent inhibition of edema & Std. deviation & One way ANOVA \\
\hline Control & 0.2 & & 0.07 & \multirow{4}{*}{$\mathrm{p}=0.058$} \\
\hline Dipyridamole & 0.09 & $11.97 \%$ & 0.12 & \\
\hline Indomethacin & 0.06 & $21.12 \%$ & 0.08 & \\
\hline Dipyridamole and Indomethacin & 0.05 & $22.53 \%$ & 0.11 & \\
\hline
\end{tabular}

Table 3: Mean pre and post paw volume in different groups of chronic experimental models.

\begin{tabular}{|c|c|c|c|c|c|c|}
\hline \multirow{2}{*}{ Chronic Inflammation groups } & & \multirow{2}{*}{ Mean } & \multirow{2}{*}{ Std. deviation } & \multicolumn{2}{|c|}{ Paired differences } & \multirow{2}{*}{$\begin{array}{l}\text { Paired t test } \\
\text { p-value }\end{array}$} \\
\hline & & & & Mean & Std. deviation & \\
\hline \multirow{2}{*}{ Control } & Pre & 1.23 & 0.11 & \multirow{2}{*}{0.25} & \multirow{2}{*}{0.10} & \multirow{2}{*}{0.002 (significant) } \\
\hline & Post & 1.48 & 0.09 & & & \\
\hline \multirow{2}{*}{ Dipyridamole } & Pre & 1.19 & 0.04 & \multirow{2}{*}{0.11} & \multirow{2}{*}{0.05} & \multirow{2}{*}{0.004 (significant) } \\
\hline & Post & 1.30 & 0.08 & & & \\
\hline \multirow{2}{*}{ Indomethacin } & Pre & 1.02 & 0.09 & \multirow{2}{*}{0.03} & \multirow{2}{*}{0.06} & \multirow{2}{*}{0.315} \\
\hline & Post & 1.05 & 0.04 & & & \\
\hline Dipyridamole and indomethacin & Pre & 1.18 & 0.08 & 0.08 & 0.07 & 0.038 (significant) \\
\hline
\end{tabular}




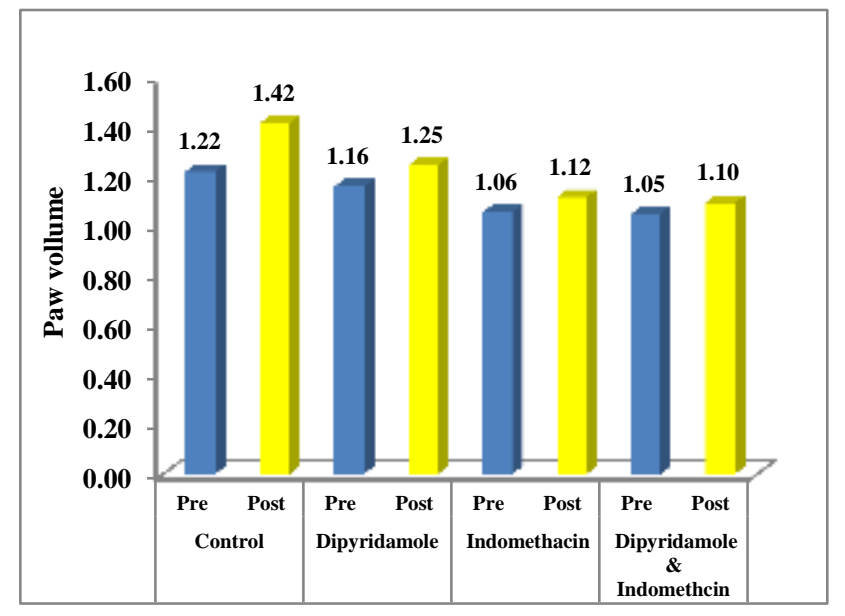

Figure 1: Mean pre and post paw volume in different groups of acute inflammation models.

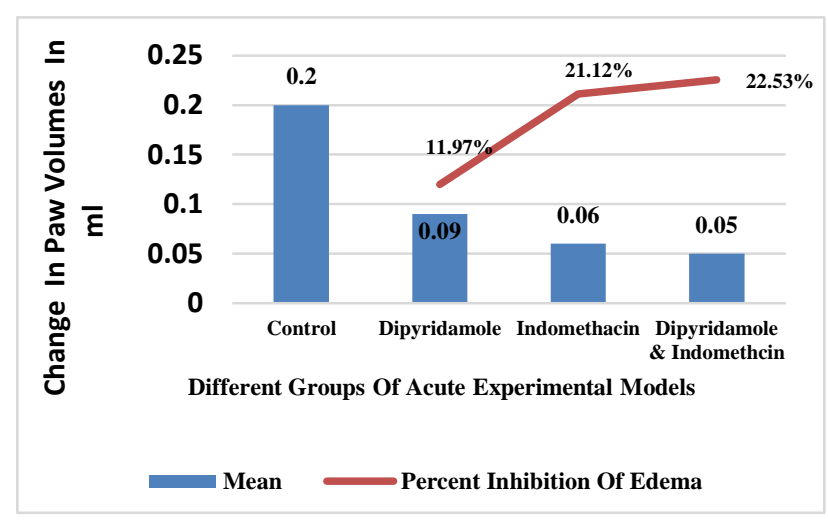

Figure 2: Mean change in paw volumes in different groups of acute experimental models.

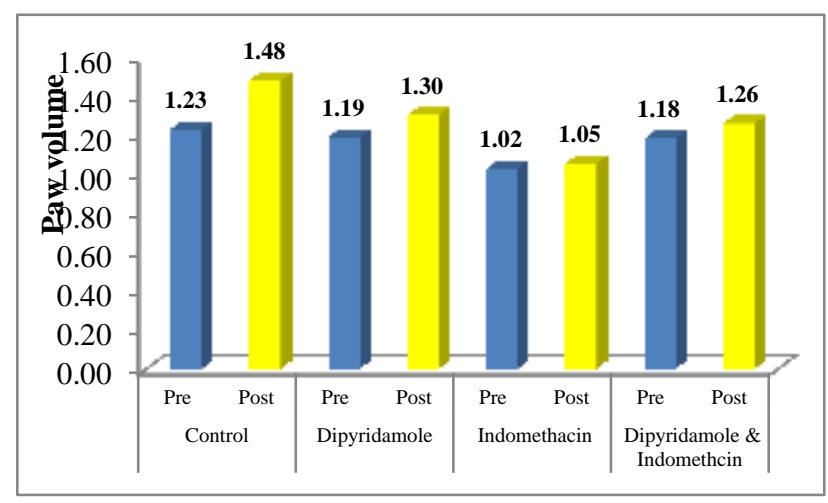

Figure 3: Mean pre and post paw volume in different groups of chronic inflammation models

\section{Formalin-induced paw edema in rats}

When both the mean pre and mean post paw volumes of chronic inflammatory models were compared, it was found that there was a statistically significant increase in mean paw volume following the administration of $4 \%$ gum acacia in control group. The values increased from $1.23 \pm 0.11$ units to $1.48 \pm 0.09$ units $(p=0.002)$; a rise of
$0.25 \pm 0.10$ units, indicating that increase in paw volume in control group was mainly due to inflammatory effect of phlogistic agent formalin. If we observe in other group such as dipyridamole and combination of both dipyridamole and indomethacin, there was a statistically significant increase in mean paw volume in dipyridamole group (from $1.19 \pm 0.04$ units to $1.30 \pm 0.08$ units, $\mathrm{p}=0.004$ ) and in Dipyridamole+Indomethacin group (from $1.18 \pm 0.08$ units to $1.26 \pm 0.09$ units, $\mathrm{p}=0.038$ ), showing not much of anti-inflammatory action.

Increase in paw volume was not significant in Indomethacin group (from $1.02 \pm 0.09$ units to $1.05 \pm 0.04$ units, $\mathrm{p}=0.315)$, due to its known anti-inflammatory action (Table 3 ).

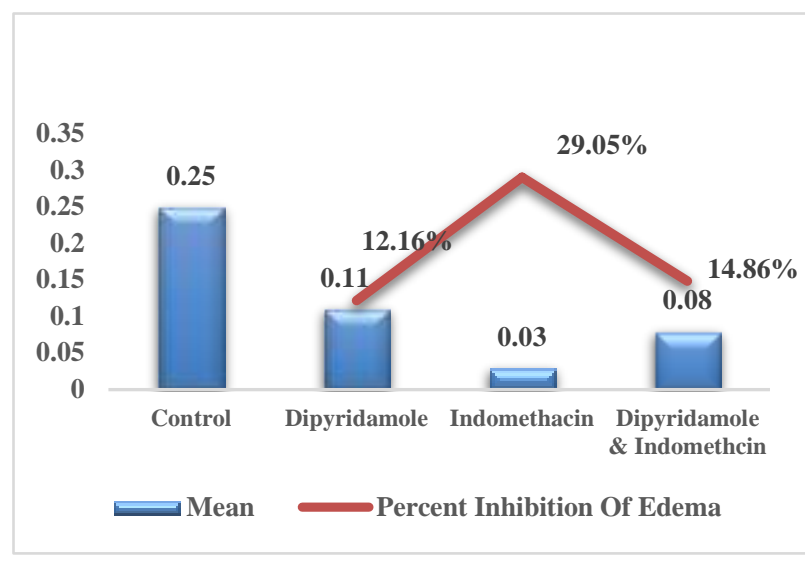

Figure 4: Mean change in paw volumes in different groups of chronic experimental models.

There was a statistically significant difference in mean change in paw volumes between groups of chronic inflammatory models as determined by one-way ANOVA $(\mathrm{p}<0.001)$. Percentage inhibition of edema was higher in Indomethacin group with inhibition of edema of around $29 \%$. Where as in dipyridamole group and Indomethacin+dipyridamole group it was around $12 \%$ and $14 \%$ respectively.

\section{Pairwise comparison (Tukey's test)}

A Tukey post-hoc test revealed that the increase in paw volume was statistically significantly lower with Dipyridamole $(0.11 \pm 0.05$ units, $\mathrm{p}=0.02)$, indomethacin $(0.03 \pm 0.06, \mathrm{p}<0.001)$ and combination of indomethacin and dipyridamole $(0.08 \pm 0.07$ units, $\mathrm{p}=0.004)$ when compared to the control group ( $0.25 \pm 0.10$ units).

There were no statistically significant differences in mean increase in paw volume between dipyridamole, indomethacin and combination of indomethacin and dipyridamole $(\mathrm{p}=0.989)$. 
Table 4: Mean change in paw volumes in different groups of chronic experimental models.

\begin{tabular}{|llll|l|}
\hline Chronic inflammation groups & Mean & Percent inhibition of edema & Std. deviation & One way ANOVA \\
\hline Control & 0.25 & & 0.1 \\
\hline Dipyridamole & 0.11 & $12.16 \%$ & 0.05 \\
\hline Indomethacin & 0.03 & $29.05 \%$ & 0.06 & 0.001 \\
\hline Dipyridamole and indomethacin & 0.08 & $14.86 \%$ & 0.07 & \\
\hline
\end{tabular}

Table 5: Pairwise comparison (Tukey's test) between groups.

\begin{tabular}{|llll|}
\hline Comparison & Mean difference & Std. error & Sig. \\
\hline Control vs dipyridamole & 0.14 & 0.04 & 0.02 (significant) \\
\hline Control vs indomethacin & 0.22 & 0.04 & $<0.001$ (significant) \\
\hline Control vs dipyridamole and indomethacin & 0.17 & 0.04 & 0.004 (significant) \\
\hline Dipyridamole vs indomethacin & 0.09 & 0.04 & 0.228 \\
\hline Dipyridamole vs dipyridamole and indomethacin & 0.03 & 0.04 & 0.864 \\
\hline Indomethacin vs dipyridamole and indomethacin & -0.05 & 0.04 & 0.632 \\
\hline
\end{tabular}

\section{DISCUSSION}

The benefits of inhibiting PDEs in disease have been known for many years but drugs inhibiting PDEs with fewer side effects have only been recently emerged. PDE inhibitors have important clinical roles as positive inotropic drugs, bronchodilators, antidepressants and antiinflammatory drugs. ${ }^{7}$ Though PDE 4 and PDE 7 are implicated in inflammation in our study dipyridamole (PDE 5 and 6 inhibitors), an antiplatelet agent was screened for its anti-inflammatory effects. ${ }^{1,6,7}$ For this, the carrageenan induced rat paw edema inhibition method for acute anti-inflammatory activity and the formalin induced rat paw edema method for testing the chronic antiinflammatory activity were employed. Inhibition of carrageenan-induced inflammation in rats is one of the most suitable test procedures used to screen antiinflammatory agents. The development of carrageenan induced oedema is bi-phasic. The first phase is attributed to the release of histamine, 5-HT and kinins while the second phase is related to the release of prostaglandins. ${ }^{8}$

Inhibition of formalin-induced pedal oedema in rats is one of the common procedures used to screen anti-arthritic and anti-inflammatory agents as it closely resembles human arthritis. ${ }^{9}$ Injection of formalin subcutaneously into the hind paw of rats produce localized inflammation and pain. The nociceptive effect of formalin is biphasic an early neurogenic component followed by a later tissue mediated response. ${ }^{10}$ Thus formalin-induced arthritis is a model used for the evaluation of an agent with probable anti-proliferative activity. This experiment is associated with the proliferative phase of inflammation.

In our study, dipyridamole showed significant antiinflammatory activity on both carrageenan induced rat paw oedema inhibition method and formalin induced rat paw edema method. This anti-inflammatory activity could be due to inhibition of platelets. Dipyridamole exerts direct anti-inflammatory effect through inhibition of platelets and platelet-monocyte interaction. ${ }^{11}$ On inhibition of platelets, it indirectly inhibits histamine and serotonin which are principle chemical mediators of the immediate phase of inflammation. Hence dipyridamole decreases edema by inhibiting vascular permeability. On inhibition of platelet-monocyte interaction it inhibits secretion of monocyte chemotactic protein-1 (MCP-1) and matrix metalloproteinase- 9 and tissue factor from monocytes. Dipyridamole has also been shown to inhibit the adhesion of neutrophils to the vascular endothelium via a specific downregulation of macrophage associated antigen-1 (Mac-1). Furthermore, dipyridamole is also involved in inhibition of lymphocyte recruitment, activation and secretion of pro inflammatory mediators, indicating its role in chronic inflammation.

In conclusion, the results obtained in our study indicate dipyridamole having anti-inflammatory action both in acute and chronic inflammatory models. Although percentage of inhibition of paw edema was seen highest, in acute inflammatory model (combination of both dipyridamole and indomethacin) statistically significant anti-inflammatory action was seen only with chronic inflammatory model. However, these results have to be substantiated by further studies using other experimental models of inflammation.

Funding: No funding sources

Conflict of interest: None declared

Ethical approval: The study was approved by the Institutional Ethics Committee

\section{REFERENCES}

1. Smith VB, Spina D, Clive P. Phosphodiesterase inhibitors. British Journal of Pharmacology. 2006;147:252-7. 
2. Theodore J, Torphy. Phosphodiesterase isozymes; molecular targets for novel antiasthma agents. Am J Respir Crit Care Med. 1998;157:351-70.

3. Moore AR, Willoughby DA. The role of cAMP regulation in controlling inflammation. Clinical and Experimental Immunology. 1995;101:387-9.

4. Beavo JA. Cyclic nucleotide phosphodiesterases: functional implications of multiple isoforms. Physiol Rev. 1995;75:725-48.

5. Winter CA, Risley EA, Nuss CW. Carrageenaninduced oedema in hind paw of the rats-an assay for anti-inflammatory drugs. Proc Soc Exp Biol Med. 1962;111:544-7.

6. Chau TT. Analgesic testing in animal models. In: Pharmacological methods in the control of inflammation. Alan R Liss Inc P. 1989:195-212.
7. Hall IP. Isoenzyme selective phosphodiesterase inhibitors: potential clinical uses. Br J Clin Pharmac. 1993;35:1-7.

8. Guptha SK. Drug screening methods. In Preclinical evaluation of new drugs. $2^{\text {nd }}$ Edition. Bengaluru: Jaypee Brothers Medical Publishers (P) Ltd; 2009:480-97.

9. Greenwald RA. Animal models for evaluation of arthritic drugs. Meth Find Clin Pharmacol. 1991;13:75-83.

10. Wheeler AH, Cowan A. Neurogenic and tissue mediated components of formalin-induced oedema. Agents Actions. 1991;34:264-9.

11. Kim HH, Liao JK. Translational therapeutics of Dipyridamole. Arterioscler Thromb Vasc Biol. 2008;28:39-42.

Cite this article as: Vishwaprakash MK, Laveesh MR, Somashekara SC. Evaluation of the antiinflammatory activity of dipyridamole in acute and chronic experimental models in albino rats. Int $\mathbf{J}$ Basic Clin Pharmacol 2016;5:1839-44. 